\title{
Fabrication and mechanical properties of boron nitride nanotube reinforced boron carbide ceramics
}

\author{
Bingsai LIU ${ }^{1,2}$, Yuanping $\mathbf{G U}^{3}$, Yuchun $\mathrm{JI}^{1,2}$, Guoyuan ZHENG ${ }^{1,2}$, Jilin WANG ${ }^{1,2, \dagger}$, Yi WU ${ }^{1,2}$, \\ Fei LONG ${ }^{1,2, \$}$ and Bing $\mathrm{ZHOU}^{1,2}$ \\ ${ }^{1}$ School of Materials Science and Engineering, Key Laboratory of New Processing Technology for Nonferrous Metals and Materials \\ of Ministry of Education, Guilin University of Technology, Guilin 541004, China \\ ${ }^{2}$ Guangxi Key Laboratory of Optical and Electronic Materials and Devices, Guilin University of Technology, Guilin 541004, China \\ ${ }^{3}$ Affiliated Stomatological Hospital, Guilin Medical University, Guilin 541004, China
}

\begin{abstract}
A series of boron nitride nanotubes (BNNTs)/ boron carbide $\left(\mathrm{B}_{4} \mathrm{C}\right)$ composite ceramics were prepared using spark plasma sintering (SPS) technology, which uses $\mathrm{B}_{4} \mathrm{C}$ powders as the matrix and BNNTs as the toughening phase. X-ray diffraction (XRD) and scanning electron microscope (SEM) were then used to characterize the $B_{4} C$ ceramic samples. The effects of the sintering temperature, the BNNTs content, and the matrix particle size on the microstructure and mechanical properties of the $\mathrm{B}_{4} \mathrm{C}$ composite ceramics were investigated in detail. The experimental results showed that the ceramic samples obtained by adding a $5 \mathrm{wt} \%$ BNNTs content sintered at $1750{ }^{\circ} \mathrm{C}$ displayed the best mechanical properties. The relative density, microhardness, and fracture toughness were 99.41\%, 32.68 GPa, and $6.87 \mathrm{Mpa} \cdot \mathrm{m}^{1 / 2}$, respectively. The fracture toughness was $54.59 \%$ higher than that of the composite without the BNNTs. The toughening mechanism of the BNNTs was also studied. The pulling-out of the BNNTs, bridging, and crack branch contributed to the toughness property of the $\mathrm{B}_{4} \mathrm{C}$-based ceramic. (C2021 The Ceramic Society of Japan. All rights reserved.
\end{abstract}

Key-words : Boron carbide, Boron nitride nanotubes, Spark plasma sintering, Mechanical property, Toughening mechanism

[Received November 20, 2020; Accepted December 10, 2020]

\section{Introduction}

Boron carbide $\left(\mathrm{B}_{12} \mathrm{C}_{3}\right.$ or $\left.\mathrm{B}_{4} \mathrm{C}\right)$ is a type of light oxide solid material, and its single hexahedron diamond crystal cell contains 15 atoms. The composition is a $\mathrm{B}_{11} \mathrm{C}$ icosahedron and a linear C-B-C three atomic chain, both of which have a covalent bond connection to form a stable structure. ${ }^{1) 2)}$ The highly stable covalent bond between the $\mathrm{B}$ and $\mathrm{C}$ atoms in $\mathrm{B}_{4} \mathrm{C}$ and its special crystalline structure makes $\mathrm{B}_{4} \mathrm{C}$ have many excellent physical and chemical properties, such as low density, high hardness, a high melting point, high temperature wear resistance, a low thermal expansion coefficient, and good thermoelectric performance, among other properties. ${ }^{3)-6)}$ These properties make $\mathrm{B}_{4} \mathrm{C}$ have broad application prospects in high-performance engineering ceramics, composite armor, body armor, and other national defense and military industry products. It is an important strategic material in today's national economy and for national defense. ${ }^{7), 8)}$ However, the high covalent bonds of the $\mathrm{B}_{4} \mathrm{C}$ content and high melting point results in $\mathrm{B}_{4} \mathrm{C}$ ceramic sintering difficulties and poor

Corresponding author: J. Wang; E-mail: jilinwang@glut. edu.cn

$\$$ Corresponding author: F. Long; E-mail: longf@glut.edu.cn toughness. These issues limit further improvements of its mechanical properties and greatly limit the application range of $\mathrm{B}_{4} \mathrm{C}$ ceramics as structural ceramics. ${ }^{9}$ )

Currently, particle toughening and whisker (fiber) toughening are effective methods to improve the fracture toughness of ceramics. Baris et al. used spark plasma sintering (SPS) technology to prepare $\mathrm{CNTs} / \mathrm{B}_{4} \mathrm{C}$ ceramic composites using carbon nanotubes (CNTs) as a toughening phase. ${ }^{10)}$ The results showed that the addition of CNTs or increasing the heating rate improved the fracture toughness of the $\mathrm{B}_{4} \mathrm{C}$ ceramics. In recent years, some studies have found that BNNTs displayed better comprehensive mechanical properties, chemical stability, and oxidation resistance than CNTs, making them an ideal toughening material. ${ }^{11), 12)}$ Zeng et al. studied the microstructure and mechanical properties of $\mathrm{BNNTs} / \mathrm{B}_{4} \mathrm{C}$ composite ceramics using the hot pressing (HP) sintering process. The results showed that the bending strength and fracture toughness of the composite with the $1.5 \mathrm{wt} \%$ BNNTs increased by 28 and $31.5 \%$, respectively. ${ }^{13), 14)}$ However, Zeng's work had the following shortcomings. (1) The $\mathrm{B}_{4} \mathrm{C}$ raw material powder used in this work was at the micron level, with large particles, low powder sintering activity, and high sintering densification temperature $\left(2050^{\circ} \mathrm{C}\right)$. (2) This work used the traditional HP sintering process to prepare the 


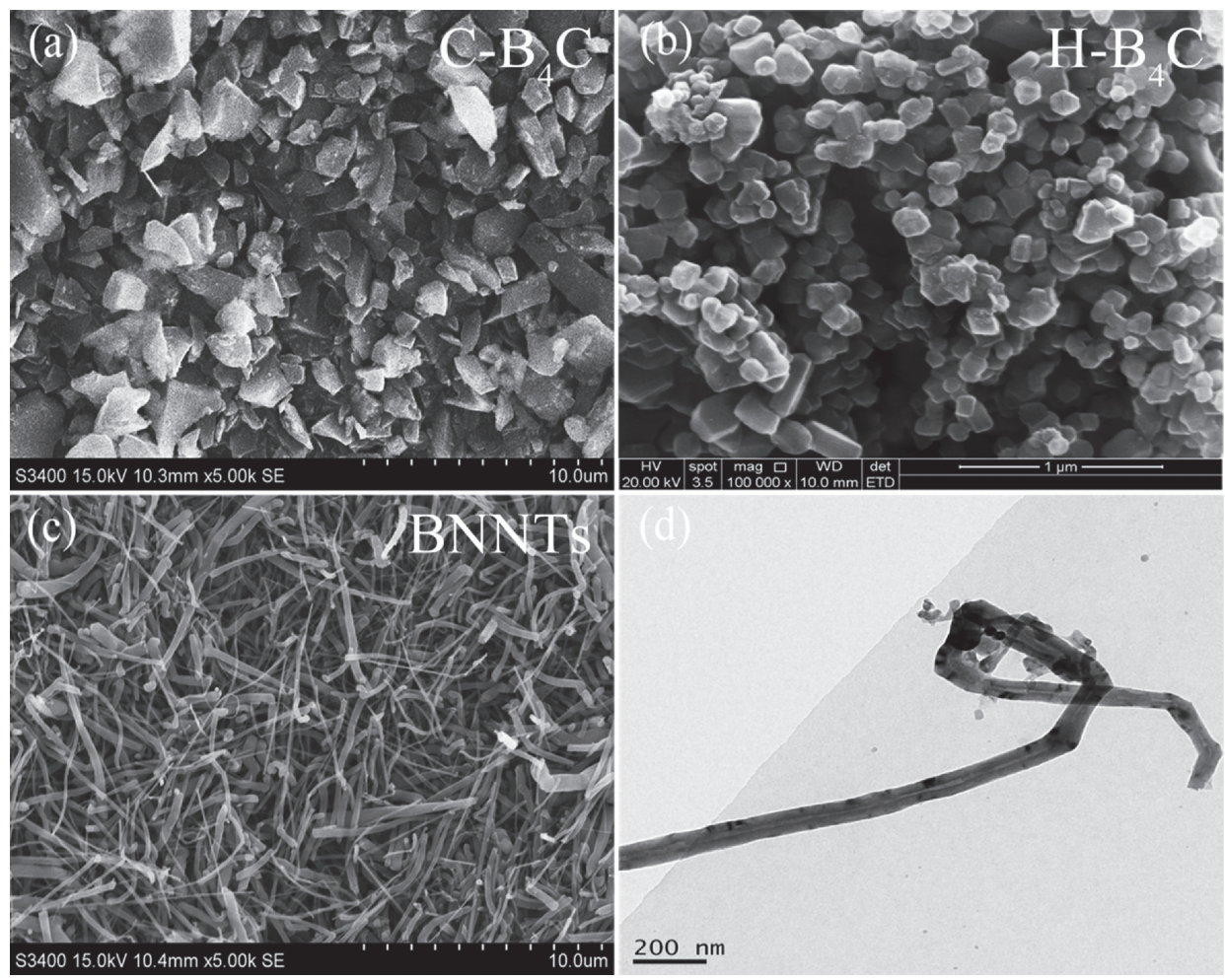

Fig. 1. The typical SEM images of (a) commercial $\mathrm{B}_{4} \mathrm{C}$, (b) homemade $\mathrm{B}_{4} \mathrm{C}$ and (c), (d) homemade BNNTs.

BNNTs $/ \mathrm{B}_{4} \mathrm{C}$ composite ceramics. The sintering cycle of the sintering process is long, and the long-term heat preservation $(1 \mathrm{~h})$ at a high temperature promotes the growth of $\mathrm{B}_{4} \mathrm{C}$ crystal grains. This results in the inability to improve the mechanical properties of the $\mathrm{B}_{4} \mathrm{C}$ ceramic products further, and the product density is low. However, compared with HP sintering technology, SPS sintering technology has the advantages of a fast heating speed, short sintering time, and low sintering temperature. In addition, due to the combined effect of plasma activation and rapid heating sintering, the growth of crystal grains is inhibited, and the microstructure of the original particles is maintained. Hence, the performance of the sintered body is essentially improved, and it is more conducive to obtaining high dense boron carbide ceramics. Therefore, in 2016, our research group prepared high-activity $\mathrm{B}_{4} \mathrm{C}$ nano-powders by coupling the self-propagating high temperature synthesis method (SHS-RC) to prepare high-density $\mathrm{B}_{4} \mathrm{C}$ ceramics (the relative density reached $99.8 \%$ ) using SPS technology and $\mathrm{B}_{4} \mathrm{C}$ nano-powders as raw materials. ${ }^{15)}$ However, this work did not explore the strengthening of the toughening of the $\mathrm{B}_{4} \mathrm{C}$ ceramic.

Therefore, in this study, high performance BNNTs $/ \mathrm{B}_{4} \mathrm{C}$ composite ceramics are prepared using SPS lowtemperature rapid sintering technology with high-activity homemade $\mathrm{B}_{4} \mathrm{C}$ nano-powders on the basis of the previous work. The influences of the sintering temperature, BNNTs content, and matrix particle size on the microstructures and mechanical properties of $\mathrm{B}_{4} \mathrm{C}$ composite ceramics are investigated. In addition, the toughening mechanism is also investigated in detail.

\section{Experimental section}

\subsection{Experimental reagents}

The commercially available micron-sized $\mathrm{B}_{4} \mathrm{C}$ powders were purchased from the Mudanjiang Boron Carbide Co., PR China [particle size of approximately $3.5 \mu \mathrm{m}$, purity $>95 \%$, Fig. 1(a)]. In addition, the $\mathrm{B}_{4} \mathrm{C}$ nano-powders [particle size of approximately $100 \mathrm{~nm}$ prepared using the SHS-RC method, purity $>99 \%$, Fig. 1(b) $]^{15)}$ and the BNNTs [these nanotubes had a bamboo-like structure with uniform diameters approximately $90 \mathrm{~nm}$ and lengths of more than $10 \mu \mathrm{m}$ prepared using the self-propagating hightemperature synthesis method, as shown in Figs. 1(c) and $1(d)^{16), 17)}$ ] were homemade in the laboratory.

\subsection{Preparation of the BNNTs $/ \mathrm{B}_{4} \mathrm{C}$ composite ceramics}

The raw materials and pre-heat treatment consisted of the following. First, the $\mathrm{B}_{4} \mathrm{C}$ and BNNTs were mixed at a certain proportion. The mixture was then put into a mixing tank and ground for $6 \mathrm{~h}$. Finally, the obtained mixture was pickled using hydrochloric acid $(12 \mathrm{~mol} / \mathrm{L}, 20 \mathrm{ml}$, to remove impurities), water washed, ethanol washed, suction filtrated, and vacuum dried and stored.

The SPS procedure consisted of taking the mixture out of the vacuum drying oven, weighing an appropriate amount of the mixture and grinding for $15 \mathrm{~min}$, and then placing the ground mixture into a graphite mold with a diameter of $15 \mathrm{~mm}$ for the SPS. The temperature, heating rate, sintering atmosphere, sintering pressure and the holding time were $1700^{\circ} \mathrm{C}, 200^{\circ} \mathrm{C} / \mathrm{min}$, vacuum-sintering, 30 
Table 1. Experimental technical parameters of the sample

\begin{tabular}{|c|c|c|c|c|}
\hline \multirow{2}{*}{$\begin{array}{c}\text { Formulation } \\
\text { S1 }\end{array}$} & \multirow{2}{*}{$\frac{\mathrm{B}_{4} \mathrm{C} \text { types }}{\mathrm{C}-\mathrm{B}_{4} \mathrm{C}}$} & \multicolumn{2}{|c|}{$\begin{array}{c}\mathrm{B}_{4} \mathrm{C} \text { content } / \mathrm{wt} \% \\
\text { BNNTs content } / \text { wt } \%\end{array}$} & \multirow{2}{*}{$\begin{array}{c}\begin{array}{c}\text { Sintering } \\
\text { temperature } /{ }^{\circ} \mathrm{C}\end{array} \\
1700\end{array}$} \\
\hline & & 100 & 0 & \\
\hline S2 & $\mathrm{C}-\mathrm{B}_{4} \mathrm{C}$ & 95 & 5 & 1700 \\
\hline $\mathrm{S} 3$ & $\mathrm{C}-\mathrm{B}_{4} \mathrm{C}$ & 90 & 10 & 1700 \\
\hline $\mathrm{S} 4$ & $\mathrm{H}-\mathrm{B}_{4} \mathrm{C}$ & 100 & 0 & 1700 \\
\hline S5 & $\mathrm{H}-\mathrm{B}_{4} \mathrm{C}$ & 95 & 5 & 1700 \\
\hline S6 & $\mathrm{H}-\mathrm{B}_{4} \mathrm{C}$ & 90 & 10 & 1700 \\
\hline S8 & $\mathrm{H}-\mathrm{B}_{4} \mathrm{C}$ & 95 & 5 & 1600 \\
\hline S9 & $\mathrm{H}-\mathrm{B}_{4} \mathrm{C}$ & 95 & 5 & 1750 \\
\hline $\mathrm{S} 10$ & $\mathrm{H}-\mathrm{B}_{4} \mathrm{C}$ & 95 & 5 & 1800 \\
\hline
\end{tabular}

$\mathrm{MPa}$, and $5 \mathrm{~min}$, respectively. After the sintering, the graphite layer on the surface of the sintered sample was removed, then polished, ultrasonically cleaned and dried to perform related test and characterization. The experimental technical parameters are shown in Table $\mathbf{1}$.

\subsection{Characterization}

The microstructure of the BNNTs powders, $\mathrm{B}_{4} \mathrm{C}$ powders, and fracture surfaces of the ceramic bulk sample was characterized using a scanning electron microscope (SEM, FEI Quanta FEG 250 and Hitachi S-3400). The sample preparation process consisted of sticking the powders or block sample directly on the conductive tape and then spraying with platinum. The phase constituent of the BNNTs powders, the $\mathrm{B}_{4} \mathrm{C}$ powders, and the fracture surfaces of the ceramic bulk sample was characterized using X-ray diffraction (XRD, Rigaku D/MAX-LLIA XRD meter with $\mathrm{Cu}-\mathrm{K} \alpha$ radiation). The microstructure of the BNNTs powders was observed using a transmission electron microscope (JEOL-2010F, Tokyo, Japan). The relative density of the sintered sample was measured using the Archimedes method. A Vickers hardness tester and the indentation method were used to test the microhardness and fracture toughness (430 Vickers Hardness Tester, Walbert, USA). The extrinsic load and dwell time of the hardness test were $5 \mathrm{~N}$ and $10 \mathrm{~s}$, respectively. The extrinsic load and dwell time of the fracture toughness test were $15 \mathrm{~N}$ and $15 \mathrm{~s}$, respectively. In addition, five positions on the top and bottom surfaces were tested to determine the average values of the microhardness and the fracture toughness test, respectively.

\section{Results and discussion}

\subsection{The influence of the type of $\mathrm{B}_{4} \mathrm{C}$ powder and the content of the BNNTs}

Figure 2 is the XRD pattern of the $\mathrm{B}_{4} \mathrm{C}$ samples fabricated using sintering at $1700^{\circ} \mathrm{C}$ with various contents of BNNTs. It can be seen from Fig. 2 that there were obvious XRD characteristic diffraction peaks of $\mathrm{B}_{4} \mathrm{C}$ and h-BN in the samples of the C-B ${ }_{4} \mathrm{C}-5 \mathrm{wt} \%$ BNNTs and the C-B $\mathrm{C}$ $10 \mathrm{wt} \%$ BNNTs. This showed that the content of amorphous carbon in the $\mathrm{C}-\mathrm{B}_{4} \mathrm{C}$ powders was relatively low. For the $\mathrm{H}-\mathrm{B}_{4} \mathrm{C}-5 \mathrm{wt} \%$ BNNTs and $\mathrm{H}-\mathrm{B}_{4} \mathrm{C}-10 \mathrm{wt} \%$ BNNTs samples, there were obvious graphitic carbon peaks in the corresponding XRD spectra. This showed that part of the

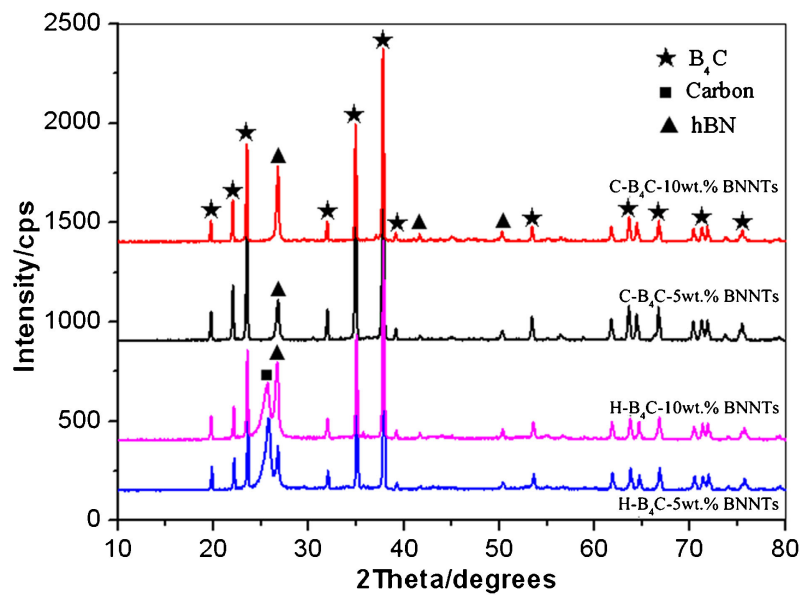

Fig. 2. XRD patterns of $\mathrm{B}_{4} \mathrm{C}$ samples fabricated by sintering at $1700^{\circ} \mathrm{C}$ with different content of BNNTs (wt \%).

amorphous carbon contained in the $\mathrm{H}-\mathrm{B}_{4} \mathrm{C}$ powders was transformed into crystalline carbon (graphite) under hightemperature conditions.

The fracture morphologies of the ceramic samples with different ceramic matrices and different BNNTs contents are shown in Fig. 3. It can be seen from Fig. 3 that all the sample sections showed low porosities and high densities. It can be seen from Fig. 3(a) that there were some pores of approximately $0.5 \mu \mathrm{m}$ (shown in the white square wireframe) and a small number of white impurity particles (shown in the white loop wireframe) on the fracture surface of the $\mathrm{C}-\mathrm{B}_{4} \mathrm{C}$ ceramic. It was also found that the section of the $\mathrm{C}-\mathrm{B}_{4} \mathrm{C}$ sample was flat, and it was speculated that the primary fracture mode was a transgranular fracture. With the addition of BNNTs, the C-B ${ }_{4} \mathrm{C}-5 \mathrm{wt} \%$ BNNTs and $\mathrm{C}-\mathrm{B}_{4} \mathrm{C}-10 \mathrm{wt} \%$ BNNTs samples appeared to have some intergranular fractures [Figs. 3(c) and 3(e)], indicating that the addition of BNNTs of certain content may have changed the fracture mode of the $C-B_{4} C$ ceramics. When the content of the BNNTs was too high, the agglomeration between the nanotubes was significant [Fig. 3(e)]. This type of agglomeration was equivalent to micron-sized defects, and this type of loose agglomerate will also produce more void defects at the junction of the nanotube and the matrix, which will hinder the densification of the matrix. ${ }^{13), 18)}$

In contrast, the fracture mode of the $\mathrm{H}-\mathrm{B}_{4} \mathrm{C}-\mathrm{BNNT}$ ceramics prepared using $\mathrm{H}-\mathrm{B}_{4} \mathrm{C}$ powders as the raw material did not change with the addition of the BNNTs. These had an intergranular fracture mode. The sintered $\mathrm{H}-\mathrm{B}_{4} \mathrm{C}$ ceramics had a nearly fully dense fracture surface and were free of impurities [Figs. 3(b), 3(d), and 3(f)]. It should be noted that the fracture surface of the $\mathrm{H}-\mathrm{B}_{4} \mathrm{C}$ and $\mathrm{H}-\mathrm{B}_{4} \mathrm{C}$ $5 \mathrm{wt} \%$ BNNTs ceramics showed that some grooves had formed after the $\mathrm{B}_{4} \mathrm{C}$ grains were pulled out during the fracture process of the sample [shown in the square wireframe in Figs. 3(b) and 3(d)]. The fracture surface of the $\mathrm{B}_{4} \mathrm{C}$ BNNTs composite ceramics showed the phenomenon of the nanotube pull-out. Hence, it is speculated that the fiber pull-out effect was included in the toughening method. 

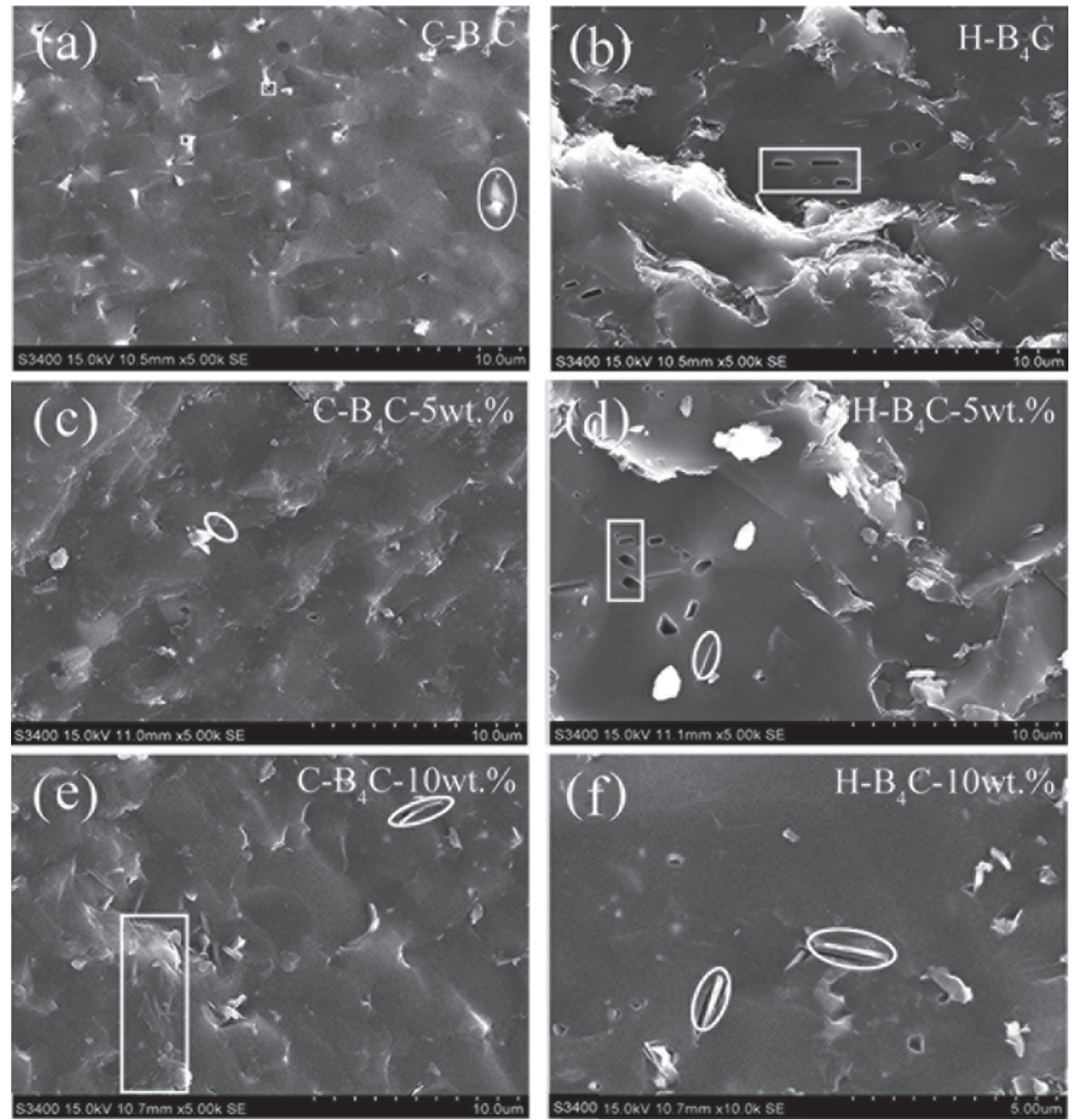

Fig. 3. SEM images of the fracture surfaces of $\mathrm{B}_{4} \mathrm{C}$ samples by sintering at $1700^{\circ} \mathrm{C}$ fabricated with different content of BNNTs.

It can be seen from Fig. 4(a) that when the contents of the BNNTs were the same, the $\mathrm{B}_{4} \mathrm{C}$-based ceramic composite material with $\mathrm{H}-\mathrm{B}_{4} \mathrm{C}$ nano-powders as the matrix had a higher relative density than the $\mathrm{B}_{4} \mathrm{C}$-based ceramic composite material with the $\mathrm{C}-\mathrm{B}_{4} \mathrm{C}$ powders as the matrix. The reason may have been that the particles of the $\mathrm{H}-\mathrm{B}_{4} \mathrm{C}$ nano-powders were much smaller than the micron-sized $\mathrm{C}-\mathrm{B}_{4} \mathrm{C}$ powders particles under the same conditions, and the smaller the particle size of the raw material, the more conducive it is to obtaining high-density ceramic samples. When the $\mathrm{C}-\mathrm{B}_{4} \mathrm{C}$ was used as the matrix, the relative density of the $\mathrm{B}_{4} \mathrm{C}$-BNNTs ceramic composite material increased accordingly with an increase in the BNNTs content. The reason is that BNNTs have a relatively small particle size and during the ceramic sintering process, the BNNTs easily fill the gaps between the $\mathrm{B}_{4} \mathrm{C}$ micron grains. In contrast to this, when $\mathrm{H}-\mathrm{B}_{4} \mathrm{C}$ was used as the matrix, the relative density of the $\mathrm{B}_{4} \mathrm{C}$-BNNTs ceramic composite material decreased slightly with an increase in the BNNTs content. ${ }^{19)}$ It is possible that the particle size of the BNNTs and $\mathrm{H}-\mathrm{B}_{4} \mathrm{C}$ nano-powders were at the same level, and the relative density of the three were close to the theoretical density. Therefore, the relative density of ceramics had little influence.

It can be seen from Fig. 4(b) that under the same conditions, when $\mathrm{H}-\mathrm{B}_{4} \mathrm{C}$ was used as the matrix, it had a higher hardness than $\mathrm{C}-\mathrm{B}_{4} \mathrm{C}$. The reason may have been that the particle size of the $\mathrm{H}-\mathrm{B}_{4} \mathrm{C}$ powders is a nanometer, while the particle size of the $\mathrm{C}-\mathrm{B}_{4} \mathrm{C}$ powders is a micrometer. Under the same conditions, the smaller the particle size of the raw material, the more conducive it is to obtaining ceramic samples with high density and high hardness. When the matrix was the same, with an increase in the BNNTs content, the hardness of the ceramic composite material gradually decreased. The reason may have been that as the content of the BNNTs continued to increase, the possibility of nanotube agglomeration became higher, and the defects and matrix pores introduced by agglomerations 

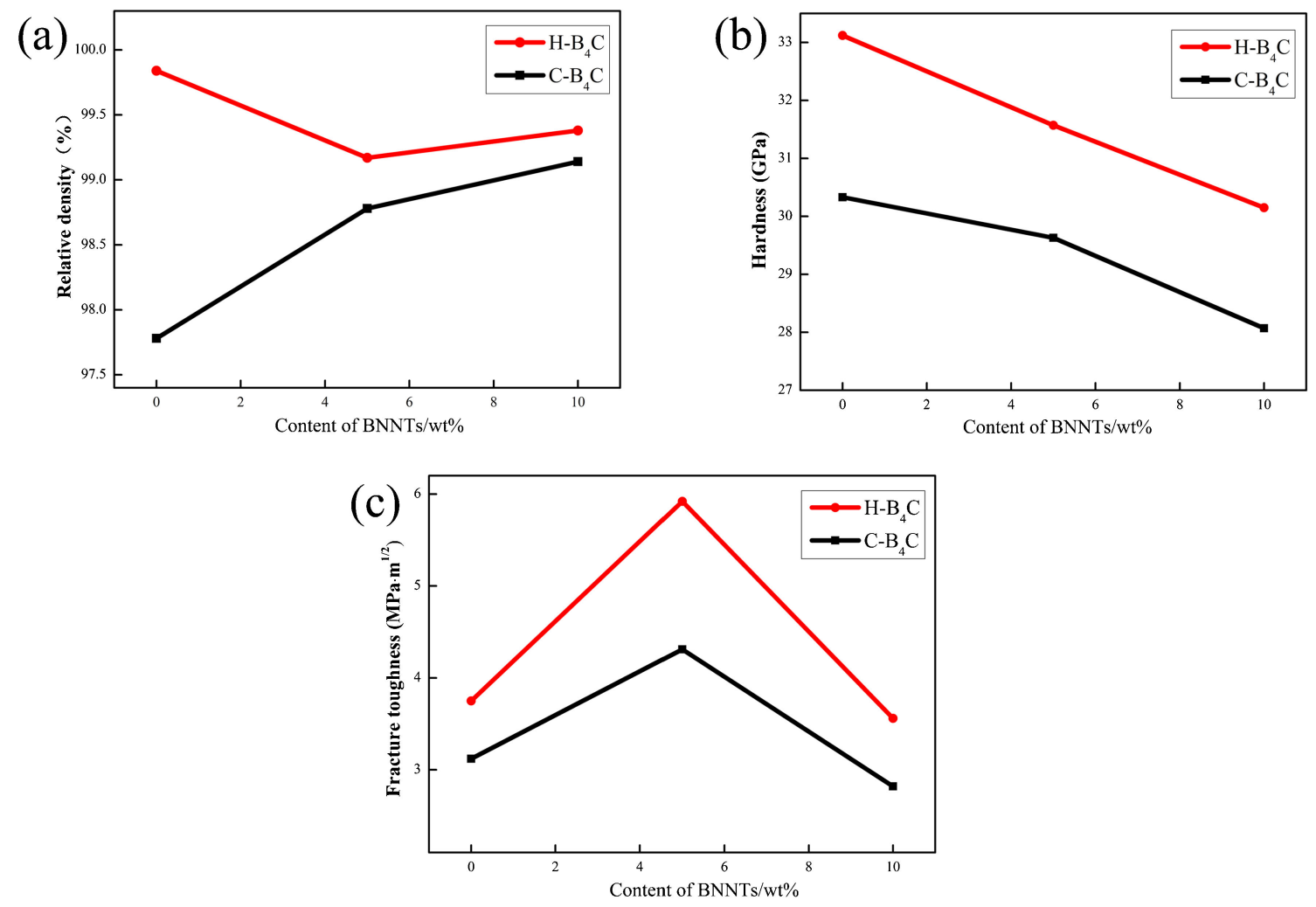

Fig. 4. The relative densities, microhardness and fracture toughness of $\mathrm{B}_{4} \mathrm{C}$ samples prepared by sintering at $1700{ }^{\circ} \mathrm{C}$ with different content of BNNTs.

increased. This would reduce the continuity and density of the ceramic matrix, which would eventually lead to a decrease in the hardness of the ceramic material. ${ }^{20}$ ) In general, although the introduction of the BNNTs reduced the hardness of the $\mathrm{B}_{4} \mathrm{C}$ ceramics, the reduced value was not very large. Hence, the introduction of the BNNTs did not have a great influence on the hardness of the $\mathrm{B}_{4} \mathrm{C}$ ceramics.

It can be seen from Fig. 4(c) that whether the ceramic matrix is $\mathrm{C}-\mathrm{B}_{4} \mathrm{C}$ or $\mathrm{H}-\mathrm{B}_{4} \mathrm{C}$, as the content of BNNTs increased, the fracture toughness of the composite ceramics first increased and then decreased. When the content of BNNTs was $5 \mathrm{wt} \%$, the fracture toughness of $\mathrm{C}-\mathrm{B}_{4} \mathrm{C}$ BNNTs and $\mathrm{H}-\mathrm{B}_{4} \mathrm{C}-\mathrm{BNNTs}$ ceramics were both the best, respectively 4.31 and $5.92 \mathrm{Mpa} \cdot \mathrm{m}^{1 / 2}$. The results showed that adding an appropriate content of BNNTs could effectively improve the fracture toughness of $\mathrm{B}_{4} \mathrm{C}$ ceramics. The reason is that BNNTs are uniformly distributed on the grain boundaries and grains of the $\mathrm{B}_{4} \mathrm{C}$ matrix. During the crack propagation process, the excellent mechanical properties of the nanotubes can effectively prevent the further propagation of the crack, thereby improving the fracture toughness of the ceramic. ${ }^{13), 21)-23)}$ However, with the further increase of the BNNTs content, the agglomeration of the nanotubes continued to increase, which caused the pores around the nanotubes to increase, which easily induced crack propagation and reduced the toughness of the composite material. Thus, the optimum BNNTs content for $\mathrm{B}_{4} \mathrm{C}$ composite ceramics in our study is determined to be $5 \mathrm{wt} \%$.
Besides, it was found that $\mathrm{H}-\mathrm{B}_{4} \mathrm{C}$ has better mechanical properties than $\mathrm{C}-\mathrm{B}_{4} \mathrm{C}$ under the same conditions.

\subsection{The influence of the sintering temperature}

It can be seen from the above experiments that the sample with the best mechanical properties was the selfmade $\mathrm{B}_{4} \mathrm{C}$-based ceramic sample with $5 \mathrm{wt} \%$ BNNTs. The relative density, hardness, and fracture toughness were $99.17 \%, 31.57 \mathrm{GPa}$, and $5.9 \mathrm{MPa} / \mathrm{m}^{2}$, respectively. Therefore, the next step was to explore the influence of the sintering temperature on the $\mathrm{H}-\mathrm{B}_{4} \mathrm{C}-5 \mathrm{wt} \%$ BNNTs ceramics.

Figure 5 illustrates the SEM patterns of the $\mathrm{H}-\mathrm{B}_{4} \mathrm{C}$ $5 \mathrm{wt} \%$ BNNTs sample sections at different temperatures. It can be seen from Fig. 5(a) that at low temperatures, there existed more pores and pits in the sintered samples, and the powder particles failed to combine with each other to form obvious grain boundaries. With an increase in the sintering temperature, the sample grains tended to fuse, and the grain size increased gradually. The pores then reduced and closed, and the density increased. When the sintering temperature reached $1750{ }^{\circ} \mathrm{C}$, the sample was nearly completely sintered. The primary reason was that as the sintering temperature increased, the process of surface diffusion and interface diffusion mass transfer sped up, the density increased, and the pores were continuously eliminated. When the sintering temperature was $1800^{\circ} \mathrm{C}$, the sample section was uneven, which may have been due to the high temperature. Also, the grain boundary migration 

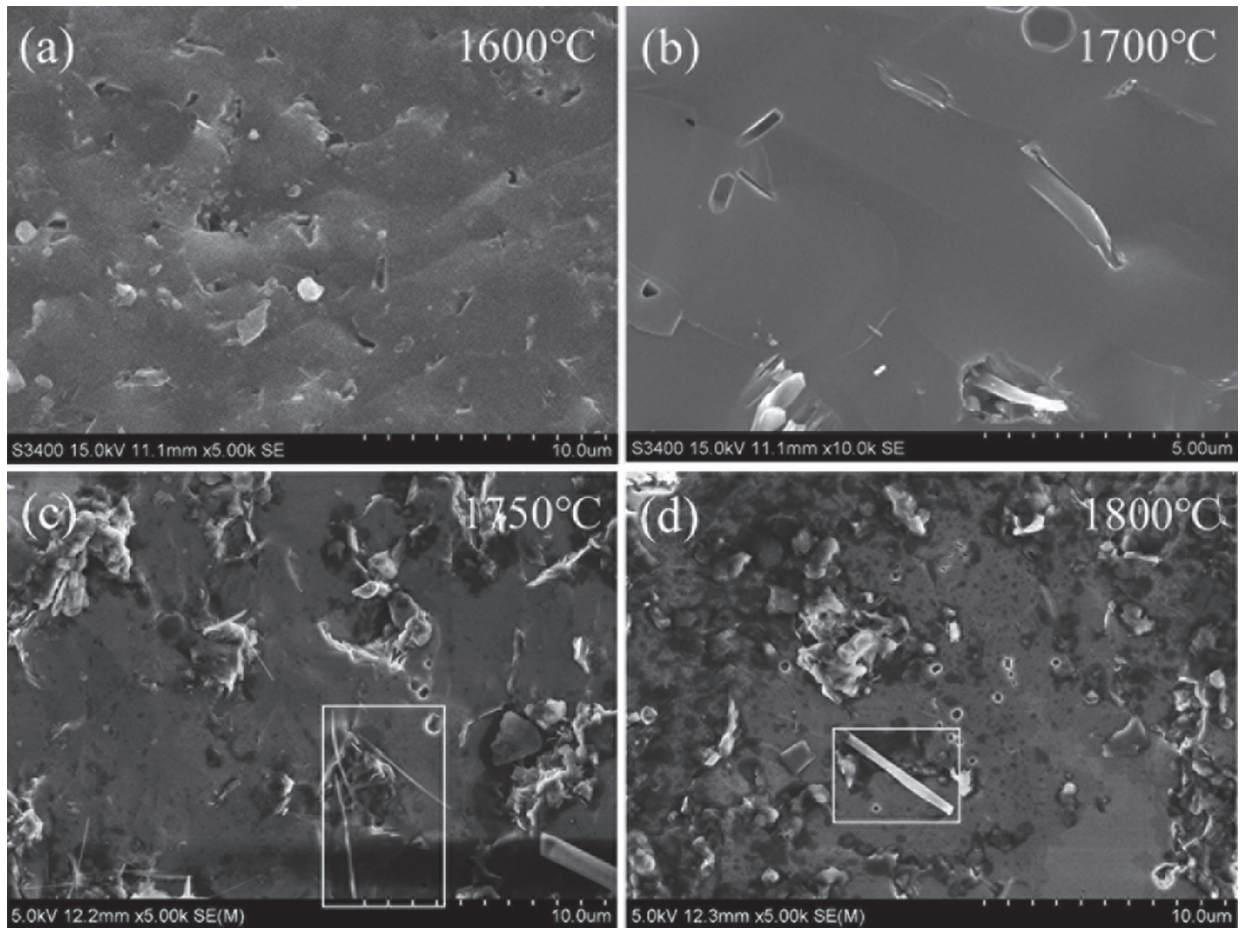

Fig. 5. SEM images of the fracture surfaces of $\mathrm{H}-\mathrm{B}_{4} \mathrm{C}$ ceramics fabricated by sintering at different temperatures with adding $5 \mathrm{wt} \%$ BNNTs.
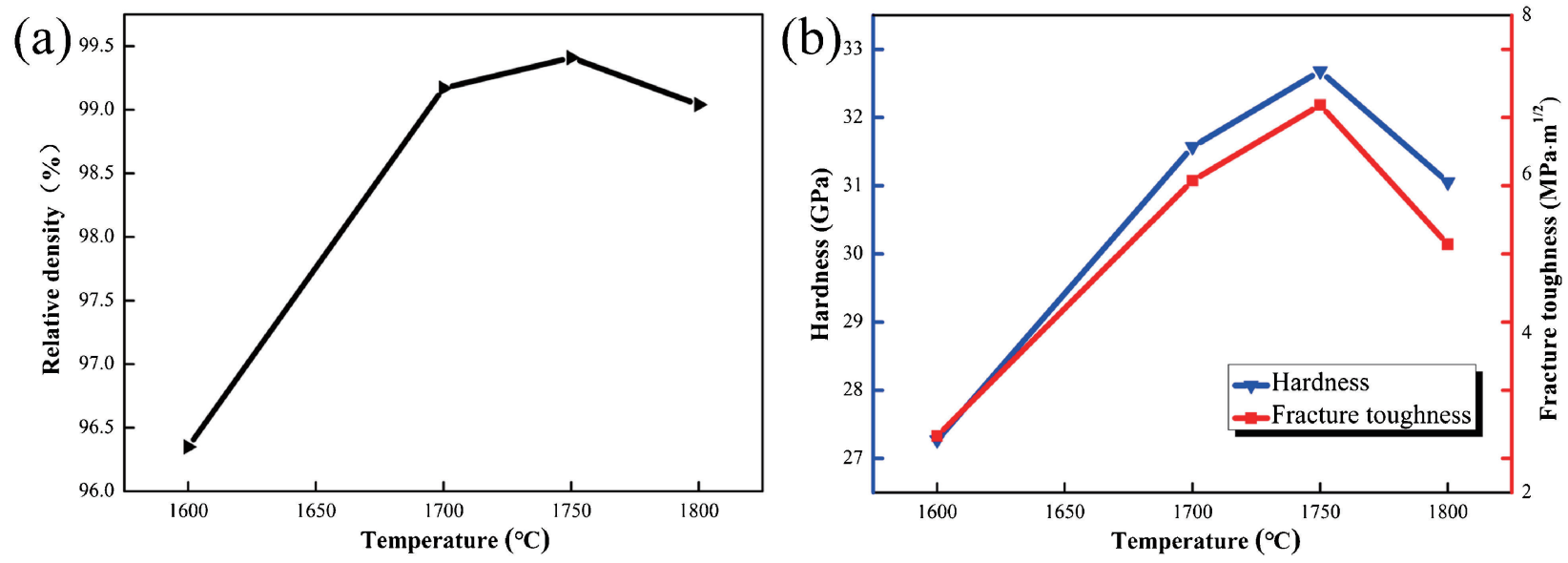

Fig. 6. The relative densities and mechanical properties of $\mathrm{B}_{4} \mathrm{C}$ samples fabricated at different sintering temperatures with adding $5 \mathrm{wt} \%$ BNNTs.

rate was greater than the pore migration rate, and the grain size increased significantly. Thus, small closed pores were formed inside the grains. ${ }^{14)}$

It can be seen from Fig. 6 that with an increase in the sintering temperature, the changing trend of the microhardness of the $\mathrm{H}-\mathrm{B}_{4} \mathrm{C}-5 \mathrm{wt} \%$ BNNTs ceramic sample was the same as the changing trend of the relative density. This indicated that the particle rearrangement of the $\mathrm{B}_{4} \mathrm{C}$ ceramic mixed with the BNNTs was enhanced during the sintering process. With an increase in the sintering temperature, the driving force of the $\mathrm{B}_{4} \mathrm{C}$ sintering continued to increase, and the continuous growth of crystal grains increased the sintering densification of the ceramics. This caused the microhardness to gradually increase. When the sintering temperature was $1750^{\circ} \mathrm{C}$, the microhardness and relative density of the sintered sample was the largest, at $99.14 \%$ and $32.68 \mathrm{GPa}$, respectively. As the temperature continued to rise, the particle size grew rapidly and more pore defects were produced. This caused a decrease in the density and hardness of the composite material.

It can be seen from Fig. 6(b) that the trend of the fracture toughness of the composite material with the sintering temperature was similar to that of the microhardness. When the temperature was lower than $1750^{\circ} \mathrm{C}$, the fracture toughness of the ceramic continued to increase as the temperature rose. When the temperature reached $1750^{\circ} \mathrm{C}$, the fracture toughness was the largest at $6.87 \mathrm{Mpa} \cdot \mathrm{m}^{1 / 2}$. Thus, the optimum sintering temperature for the $\mathrm{H}-\mathrm{B}_{4} \mathrm{C}$ - 

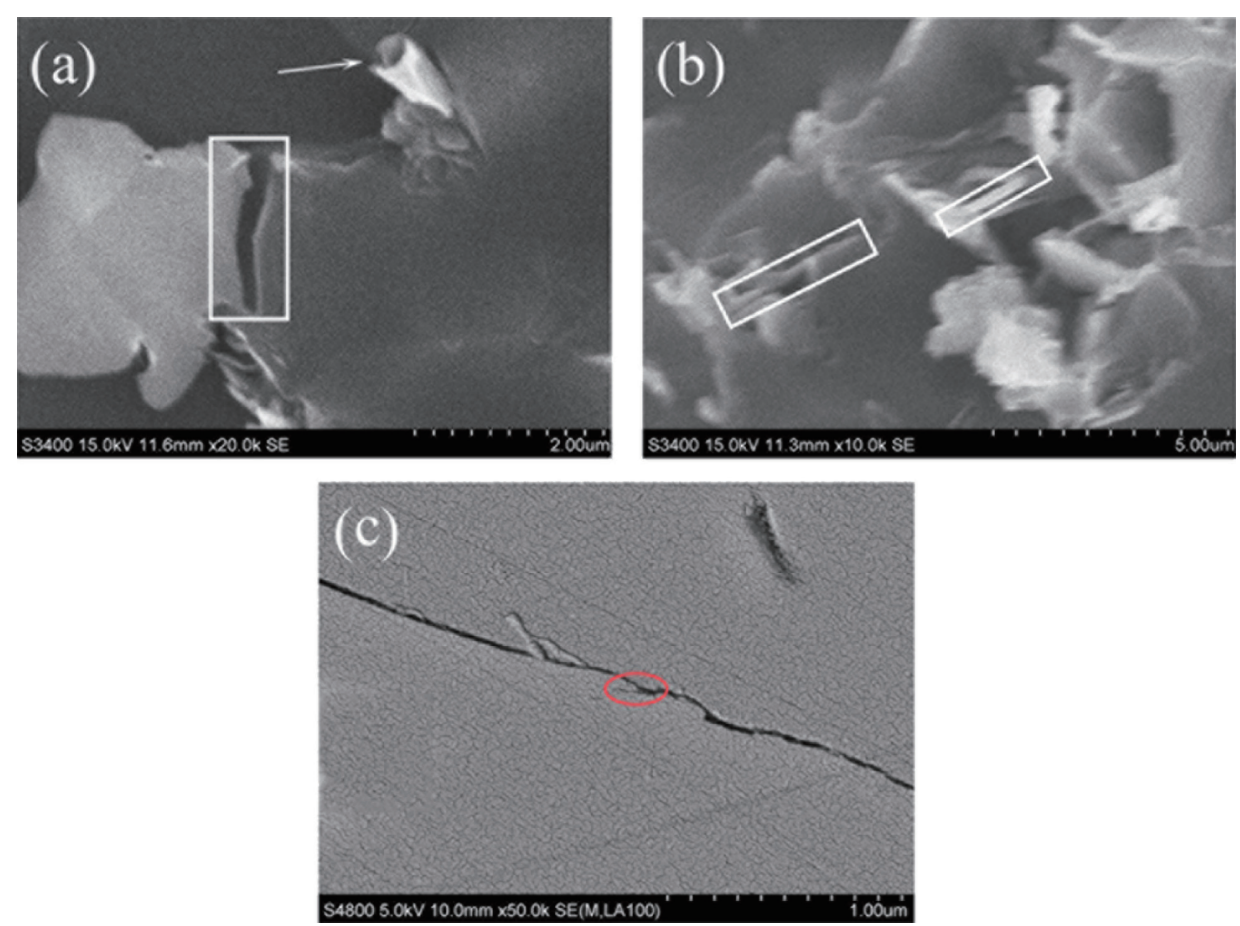

Fig. 7. SEM images of the $\mathrm{H}-\mathrm{B}_{4} \mathrm{C}-5 \mathrm{wt} \%$ BNNTs composites: (a), (b) fracture surface; (c) polished surface with cracks.

$5 \mathrm{wt} \%$ BNNTs ceramics in this study was determined to be $1750{ }^{\circ} \mathrm{C}$. The reason is this is that when the sintering temperature increased, the bonding strength of the heterogeneous interface between the BNNTs and the $\mathrm{B}_{4} \mathrm{C}$ ceramic matrix increased. When the crack extended to the surface of the nanotube, the crack propagation path or crack growth energy was increased due to crack deflection, bridging, and pull-out effects. As the temperature continued to rise, the fracture toughness of ceramic materials decreased significantly. The reason for this was that as the $\mathrm{B}_{4} \mathrm{C}$ grains grew rapidly and the toughening effect of the BNNTs was difficult to offset the abnormal growth of the $\mathrm{B}_{4} \mathrm{C}$ grains and the abnormal interface strength reduction, this led to a significant reduction in the fracture toughness of the composite material. ${ }^{19)}$

\subsection{Toughening mechanism}

Figure 7 shows the SEM micrographs of fractured surfaces and the crack propagation path of the $\mathrm{H}-\mathrm{B}_{4} \mathrm{C}-\mathrm{BNNT}$ composite. The embedding of the BNNTs and the holes left (denoted by the dotted circle) by the pulling out of the BNNTs are clearly observed, as shown in Fig. 7(a). Also, the nanotubes marked by the arrows in Fig. 7(a) show a clear hollow structure, and the phenomenon of cracking, which may have been caused by the force during the cracking process. The BNNTs prevented the cracks from propagating. The cracks continued to grow until the BNNTs were pulled out from the matrix. The heterogeneous interface between the BNNTs and the $\mathrm{B}_{4} \mathrm{C}$ ceramic had a strong bonding strength, which dissipated more fracture energy when the BNNTs were pulled out. This relaxed the stress at the crack tip and slowed down the crack prop- agation, contributing to improving the toughness. During the process of crack propagation, due to the better mechanical properties (high strength and high modulus) of the nanotubes, this can prevent the propagation of cracks or produce crack deflection. In Fig. 7(b), BNNTs were connected between the two-grain boundaries. The crack propagation path of the $\mathrm{H}-\mathrm{B}_{4} \mathrm{C}-\mathrm{BNNT}$ s composite is shown in Fig. 7(c). The crack branching were observed as indicated by the arrows in this figure (shown in the red circle wireframe). Crack bridging and crack branching were the other toughening mechanisms, except the pulling out of the BNNTs, which enhanced the toughness. ${ }^{21)}$ The reason for the improvements in the fracture toughness of the ceramics may also have been because there was a certain amount of amorphous carbon in the $\mathrm{H}-\mathrm{B}_{4} \mathrm{C}$ ceramic nanopowder. ${ }^{24)}$ During the high-temperature sintering process, the carbon may have dissolved in the $\mathrm{B}_{4} \mathrm{C}$ crystal lattice or aggregate on the $\mathrm{B}_{4} \mathrm{C}$ grain boundaries in the form of crystalline graphite particles. The carbon particles may have had a pinning effect on the grain boundaries to prevent grain growth. Additionally, carbon can also be used as a deoxidizer to inhibit the growth of pores and surface diffusion and further strengthen grain boundary diffusion.

\section{Conclusion}

A series of $\mathrm{BNNTs} / \mathrm{B}_{4} \mathrm{C}$ composite ceramics were prepared using SPS technology. Regardless of whether the $\mathrm{B}_{4} \mathrm{C}$ ceramic matrix consisted of micron-powders or nanopowders, the addition of BNNTs greatly enhanced the fracture toughness. The optimum BNNTs content was $5 \mathrm{wt} \%$. However, too much BNNTs degraded the fracture toughness of the ceramics. Moreover, the addition of a certain 
content of BNNTs had little effect on the microhardness and density of the $\mathrm{B}_{4} \mathrm{C}$-based ceramics. Under the same conditions, the $\mathrm{H}-\mathrm{B}_{4} \mathrm{C}$ as a matrix had higher mechanical properties than the $\mathrm{C}-\mathrm{B}_{4} \mathrm{C}$. The relative density, microhardness, and fracture toughness of the $\mathrm{H}-\mathrm{B}_{4} \mathrm{C}-5 \mathrm{wt} \%$ BNNTs ceramics increased with an increase in the sintering temperature, reaching $99.41 \%, 32.68 \mathrm{GPa}$, and 6.87 $\mathrm{Mpa} \cdot \mathrm{m}^{1 / 2}$ (maximum value), respectively, at $1750^{\circ} \mathrm{C}$. The toughening mechanism may have been the pull-out of BNNTs, the bridging of BNNTs, and crack branching. The results of this study provide experimental and theoretical reference for further research on the strengthening and toughening of boron carbide-based ceramics.

Acknowledgements The authors acknowledge the financial support from National Natural Science Foundation of China (No.51972071), Guangxi Natural Science Foundation (2018GXNSFAA050032), Non-Ferrous Metals and Materials Processing New Technology Ministry of Education Key Laboratory Open Fund Project (No.19KF-5 and No.19AA14), Guilin Scientific Research and Technology Development Program (No.20190204-2). We thank LetPub (www.letpub. com) for its linguistic assistance during the preparation of this manuscript.

Disclosure statement No potential conflict of interest was reported by the authors.

\section{References}

1) R. Lazzari, N. Vast, J. Besson, S. Baroni and A. Dal Corso, Phys. Rev. Lett., 83, 3230-3233 (1999).

2) F. Mauri, N. Vast and C. J. Pickard, Phys. Rev. Lett., 87, 085506 (2001).

3) T. Mori, J. Solid State Chem., 275, 70-82 (2019).

4) H. Werheit, A. Leithe-Jasper, T. Tanaka, H. W. Rotter and K. A. Schwetz, J. Solid State Chem., 177, 575-579 (2004).

5) J. L. Watts, H. J. Spratt, P. C. Talbot, J. A. Alarco and I. D. R. Mackinnon, Ceram. Int., 46, 11033-11040 (2020).

6) A. K. Suri, C. Subramanian, J. K. Sonber and T. S. R. Ch. Murthy, Int. Mater. Rev., 55, 4-40 (2020).
7) F. Thevenot, J. Eur. Ceram. Soc., 6, 205-225 (1990).

8) V. Domnich, S. Reynaud, R. A. Haber and M. Chhowalla, J. Am. Ceram. Soc., 94, 3605-3628 (2011).

9) K. Y. Xie, M. F. Toksoy, K. Kuwelkar, B. W. Zhang, J. A. Krogstad, R. A. Haber and K. J. Hemker, J. Am. Ceram. Soc., 97, 3710-3718 (2014).

10) B. Yavas, F. Sahin, O. Yucel and G. Goller, Ceram. Int., 41, 8936-8944 (2015).

11) Y. F. Chen, J. Q. Bi, W. L. Wang, Y. Zhao, G. L. You, C. L. Yin and Y. J. Bai, Mat. Sci. Eng. A-Struct., 590, 16-20 (2014).

12) W. L. Wang, J. Q. Bi, K. N. Sun, M. Du, N. N. Long and Y. J. Bai, J. Am. Ceram. Soc., 94, 3636-3640 (2011)

13) X. J. Zeng, W. L. Liu, Z. Q. Feng and J. P. Ruan, J. Ceram., 34, 438-442 (2013).

14) X. J. Zeng, W. L. Liu, Z. Q. Feng and J. P. Ruan, China Ceramics., 41, 7021-7027 (2014).

15) J. L. Wang, F. Long, W. M. Wang, S. Y. Mo, Z. G. Zou and Z. Y. Fu, Ceram. Int., 42, 6969-6977 (2016).

16) J. L. Wang, Z. L. Li, Y. L. Gu, X. W. Du, Z. X. Zhang, W. M. Wang and Z. Y. Fu, Ceram. Int., 41, 1891-1896 (2015).

17) J. L. Wang, D. J. Peng, F. Long, W. M. Wang, Y. L. Gu, S. Y. Mo, Z. G. Zou and Z. Y. Fu, Solid State Sci., 64, 23-28 (2017).

18) X. Q. Li, Y. M. Gao, W. Pan, L. C. Song, Z. C. Zhong and S. S. Wu, Ceram. Int., 41, 27-36 (2015).

19) T. Jiang, Z. H. Jin, J. F. Yang and G. J. Qiao, J. Mater. Process. Tech., 209, 561-571 (2009).

20) R. Alexander, T. S. R. Ch. Murthy, K. V. Ravikanth, J. Prakash, T. Mahata, S. Bakshi, M. Krishnan and K. Dasgupta, Ceram. Int., 44, 9830-9838 (2018).

21) M. D. Chen, Z. N. Yin, J. T. Yuan, W. W. Xu, J. D. Ye and S. Y. Yan, Ceram. Int., 44, 15370-15377 (2018).

22) W. L. Wang, J. Q. Bi, S. R. Wang, K. N. Sun, M. Du, N. N. Long and Y. J. Bai, J. Eur. Ceram. Soc., 31, 2277-2284 (2011).

23) J. J. Xu, Y. J. Bai, W. L. Wang, S. R. Wang, F. D. Han, Y. X. Qi and J. Q. Bi, Mat. Sci. Eng. A-Struct., 546, 301-306 (2012).

24) K. A. Schwetz, W. Grellner and A. Lipp, Inst. Phys. Conf. Ser. 75, 413-426 (1986). 